\title{
Thiabowls: synthesis, molecular structure and the solid state architecture of tetrathia-[4]-peristylane
}

\author{
Goverdhan Mehta, ${ }^{\mathrm{a}, *}$ Vanessa Gagliardini, ${ }^{\mathrm{a}}$ Carsten Schaefer ${ }^{\mathrm{b}}$ and Rolf Gleiter ${ }^{\mathrm{b}, *}$

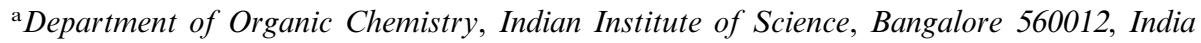 \\ ${ }^{\mathrm{b}}$ Organisch-Chemisches Institut, Universität Heidelberg, INF 270, D-69120 Heidelberg, Germany
}

\begin{abstract}
Synthesis of tetrathia-[4]-peristylane, the first thiabowl, from the dimer of cyclooctatetraene has been accomplished. The X-ray crystal structure of the tetrathiabowl indicates significant departure from the expected $C_{4 v}$ symmetry and in the solid state it exhibits a multi-columnar arrangement and a novel 'self-inclusion' phenomenon, directed by a network of $\mathrm{S} \cdots \mathrm{S}$ and $\mathrm{CH} \cdots \mathrm{S}$ interactions.
\end{abstract}

Design of aesthetically pleasing and topologically novel molecular entities, with high symmetry and shapes reminiscent of familiar objects, continues to inspire the creative instincts of synthetic chemists. ${ }^{1}$ Our continuing fascination with such systems led us to conceptualize $[n]$-hetero- $[n]$-peristylanes $\mathbf{1 - 4}$ (Scheme 1) as bowlshaped polycyclic systems constituted through the union of an $n$-membered base ring bonded to the carbon atoms of a $2 n$-membered rim with $n$-number of

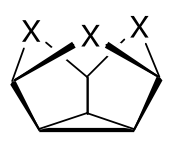

1a. $X=0$

b. $X=N R$

c. $X=S$

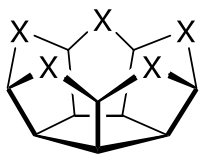

$3 a, b, c$

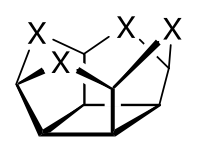

$2 a, b, c$

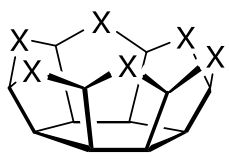

$4 a, b, c$
Scheme 1.

Keywords: cyclic thioethers; intermolecular interactions; oxygen-sulfur exchange.

* Corresponding authors. Tel.: +49 (6221) 548400; fax: +49 (6221) 544205 (R.G.); Tel.: +91-80-3602367; fax: +91-80-3600936 (G.M.); e-mail: gm@orgchem.iisc.ernet.in; rolf.gleiter@urz.uni-heidelberg.de alternating heteroatoms. The resulting $(n+1)$-membered heteropolycycles (heterobowls) 1-4 have potential $C_{n v}$ symmetry and distinct hydrophobic (base) and hydrophilic surfaces (rim) and are well poised to exhibit interesting molecular and supramolecular structural characteristics.

In pursuit of the target structures 1-4, we have recently accomplished the synthesis of triaza-[3]-peristylane $\mathbf{1 b}$, tetraoxa-[4]-peristylane $\mathbf{2 a}$ and pentaoxa-[5]-peristylane 3a. ${ }^{2,3}$ Oxaperistylanes $\mathbf{2 a}$ and $\mathbf{3 a}$ exhibit extremely interesting supramolecular architecture in the solid state dictated by a network of $\mathrm{CH} \cdots \mathrm{O}$ interactions. ${ }^{2 \mathrm{~b}-\mathrm{e}}$ These successes have spurred us to investigate the synthesis of other heterobowls, particularly of thiabowls 1c-4c. It was of interest to explore whether chalcogen-chalcogen interactions, ${ }^{4}$ besides $\mathrm{CH} \cdots \mathrm{S}$ interactions would be manifested in the solid state architecture of these novel sulphur heterocycles. We have now achieved the synthesis of the first thiabowl (tetrathia-[4]-peristylane 2c) and found that in the solid state it reveals a novel supramolecular architecture generated through a selfinclusion phenomenon and dictated by intermolecular $\mathrm{CH} \cdots \mathrm{S}$ and $\mathrm{S} \cdots \mathrm{S}$ interactions.

Our synthetic approach to tetrathia-[4]-peristylane 2c hinged on the idea of harnessing the remarkable propensity of Lawesson's reagent [2,4-bis(4-methoxyphenyl)-1,3-dithiaphosphetane-2,4-disulfide, LR] to effect oxygen-sulfur exchange in carbonyl containing substrates. ${ }^{5}$ It was anticipated that acetal groups, which are synthetically equivalent to carbonyl groups, would also undergo oxygen-sulfur exchange. ${ }^{6}$ 


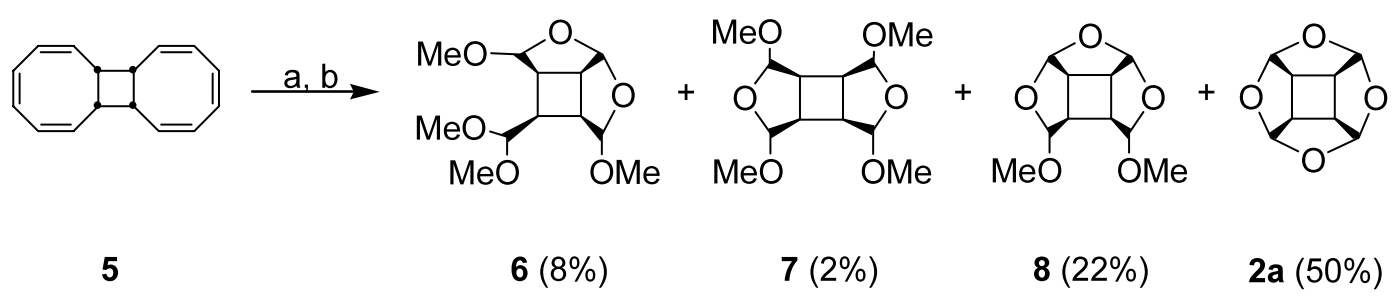

Scheme 2. Reagents: (a) $\mathrm{O}_{3}, \mathrm{DCM} / \mathrm{MeOH}: 2 / 1,-78^{\circ} \mathrm{C} ; \mathrm{Me}_{2} \mathrm{~S},-78^{\circ} \mathrm{C}$ to rt; (b) Amberlyst $15, \mathrm{rt}, 12 \mathrm{~h}$.

In this context tetraoxaperistylane $2 \mathbf{a}^{2 b}$ and its precursor acetals appeared to be serviceable precursors for the proposed heteroatom-exchange with LR. Consequently, the $[2+2]$ dimer 5 of cyclooctatetraene ${ }^{7}$ was subjected to ozonolysis and further stirring with Amberlyst 15 resin to furnish cyclic acetals $6(8 \%), 7(2 \%), 8(22 \%)$ and the tetraoxaperistylane $\mathbf{2 a}(50 \%)$, Scheme $2 .^{8}$

When $\mathbf{6 - 8}$ or $\mathbf{2 a}$ were treated with LR under sonication conditions, tetrathia-[4]-peristylane 2c was formed in each case in yields ranging from $10 \%$ from 6 to trace amounts from $\mathbf{2 a}$ (Scheme 3 ). Although the yields leading to $\mathbf{2 c}$ are very low, it is quite remarkable that all four sulfur atoms, replacing the existing oxygens in the precursors, are positioned along with concomitant cyclisations in a single pot operation. ${ }^{6}$

The ${ }^{1} \mathrm{H}$ and ${ }^{13} \mathrm{C}$ NMR spectra of $2 \mathrm{c}$ exhibited two signals each (Table 1), as expected for the $C_{4 v}$ symmetric structure. However, the observed chemical shifts were somewhat deviated from the expected range. The calculated NMR chemical shifts for the $C_{4 v}$ optimized structure $^{9,10}$ of $2 \mathbf{c}$ are compared with those experimentally observed and while the proton chemical shifts are reproduced well, at various levels of theory, the carbon chemical shifts exhibit considerable differences and it is not clear whether these can be attributed to the limitations of the computational methods or are due to the intrinsic geometrical distortions present in $\mathbf{2 c}$ as observed in the X-ray crystal structure (vide infra).

The X-ray data ${ }^{11}$ of $2 c$ revealed that its needle shaped crystals belong to the $P 2 / C$ space group with two crystallographically independent molecules in the asymmetric unit (designated hereafter as $\mathbf{A}$ and $\mathbf{B}$ ) and are oriented at $\sim 50^{\circ}$ to each other. Details of the molecular geometry, particularly the transannular sulfur-sulfur distances in the independent molecules $\mathbf{A}$ and $\mathbf{B}$, indicated marked deviation from the expected $C_{4 v}$ symmetry to $C_{\mathrm{s}}$ symmetry with an ellipsoidal shape. A

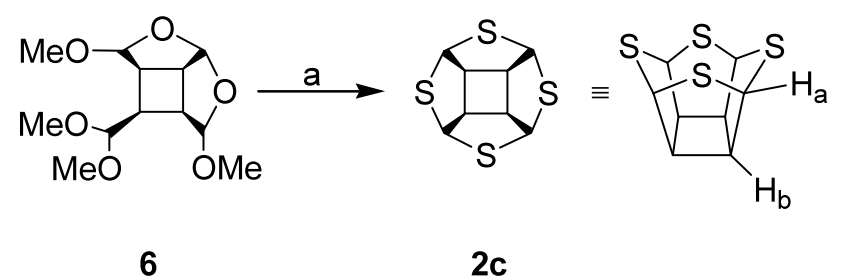

Scheme 3. Reagents: (a) Lawesson's reagent, PhMe, sonication, rt, $12 \mathrm{~h}, 10 \%$. comparison of the calculated and observed sulfur-sulfur distances and the resulting distortion in shape are shown in Figure 1 (calculated) and Figure 2 (ORTEP). The X-ray crystal structure of $\mathbf{2 c}$ also indicated significant difference in the geometrical distortion in the two independent molecules $\mathbf{A}$ and $\mathbf{B}$ in the unit cell from the expected $C_{4 v}$ symmetry (see Fig. 2). ${ }^{12}$

The packing pattern in thiabowl $\mathbf{2 c}$ reveals a large number of close intermolecular contacts among molecules of $\mathbf{A}$ and $\mathbf{B}$ as well as molecules $\mathbf{A}$ that are within the range of Van der Waals interactions and $\mathrm{CH} \cdots \mathrm{S}$ hydrogen bonds. ${ }^{13-15}$ The molecules are arranged in a two dimensional ABAABA type ensemble such that the molecules $\mathbf{B}$ are intercalated between the columns of $\mathbf{A}$ molecules (Fig. 3). When viewed along the $c$-axis, the $\mathbf{A}$ molecules stack on top of each other, in a top to bottom fashion, in a columnar architecture growing in opposite directions (Fig. 4). While the A molecules in the columns are held together through $\mathrm{CH} \cdots \mathrm{S}$ contacts $\left(2.93 \AA\right.$, angle $\left.130.4^{\circ}\right)$ between the cyclobutane hydrogen of the base and the sulphur atom of the rim of the next bowl in the same column, the AA pattern of columns growing in opposite directions is supported by robust $\mathrm{S} \cdots \mathrm{S}$ contacts $(3.29 \AA)$ (Fig. 3). There is also an additional short $\mathrm{CH} \cdots \mathrm{S}$ contact $\left(2.92 \AA\right.$, angle $\left.155.9^{\circ}\right)$ between the cyclobutane hydrogen and the rim sulphur in the adjacent column of A molecules, growing in the opposite direction, that further sustains the 'rim-up, rim-down' columnar arrangement (Fig. 5). The $\mathbf{B}$ molecules on the other hand do not engage in any appreciable short contact between them. However they too define a columnar top to bottom arrangement that is held in place through $\mathrm{S} \cdots \mathrm{S}$ contacts $(3.62$ and $3.61 \AA$ ) with columns of $\mathbf{A}$ molecules (Figs. 3 and 4).

It is noteworthy that all four sulfur atoms within the $\mathbf{B}$ molecules of $\mathbf{2 c}$ are involved in $\mathrm{S} \cdots \mathrm{S}$ contacts with the neighboring A molecules. This kind of packing of $\mathbf{B}$ molecules can be considered as a self-inclusion process as $\mathbf{A}$ and $\mathbf{B}$ are symmetry independent molecules. In other words, thiabowl $\mathbf{2 c}$ in the solid state can be regarded as a 'host-guest complex' in which B molecules, in a columnar fashion, are encapsulated between the columns of $\mathbf{A}$ molecules. In contrast to $\mathbf{B}$ molecules, only three sulfur atoms of $\mathbf{A}$ molecules participate in $\mathrm{S} \cdots \mathrm{S}$ contacts and one of them in a bifurcated manner, being involved in both $\mathrm{CH} \cdots \mathrm{S}(2.93$ $\AA$ ) and $\mathrm{S} \cdots \mathrm{S}$ contacts (3.61 $\AA$ ) (Fig. 3). To our knowledge, this is a rare case of bifurcated engagement of sulfur atoms in both the $\mathrm{S} \cdots \mathrm{S}$ and $\mathrm{CH} \cdots \mathrm{S}$ contacts. 
Table 1. Observed and calculated ${ }^{1} \mathrm{H}$ and ${ }^{13} \mathrm{C}$ NMR shifts for $2 \mathbf{c}$

\begin{tabular}{llllll}
\hline Nuclei & & Experiment & B3LYP/6-311+G(2d,p) & B3LYP/6-311++G(2df,p) & B3LYP/6-311++G(3df,3pd) \\
\hline $\mathrm{H}_{\mathrm{a}}$ & $\delta$ & 5.61 & 5.75 & 5.72 & 5.81 \\
$\mathrm{H}_{\mathrm{b}}$ & $\delta$ & 4.09 & 4.01 & 3.97 & 4.00 \\
$\mathrm{C}_{\mathrm{a}}$ & $\delta$ & 69.4 & 88.79 & 84.79 & 87.29 \\
$\mathrm{C}_{\mathrm{b}}$ & $\delta$ & 58.6 & 66.21 & 62.31 & 65.64 \\
\hline
\end{tabular}

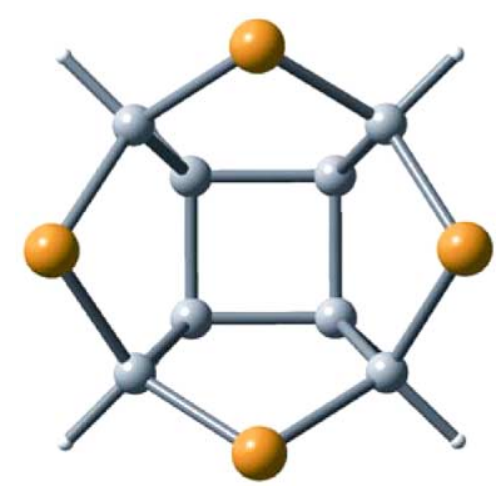

Figure 1. Optimized [B3LYP/6-311G(d)] $C_{4 \mathrm{v}}$ symmetric structure of 2c. Transannular sulfur-sulfur distance $4.466 \AA$.

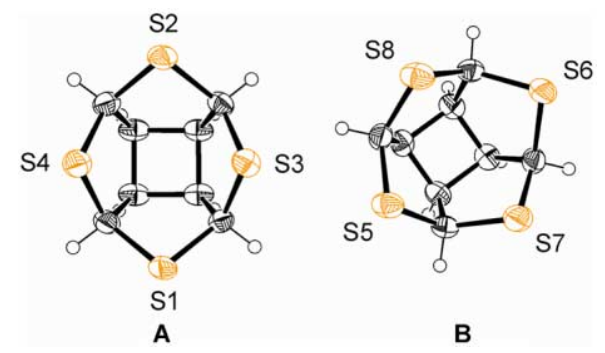

Figure 2. ORTEP drawing of 2c. Transannular sulfur-sulfur distances: Molecule A S1-S2 4.833 A, S3-S4 $3.827 \AA$; Molecule B S5-S6 4.642 A, S7-S8 4.127

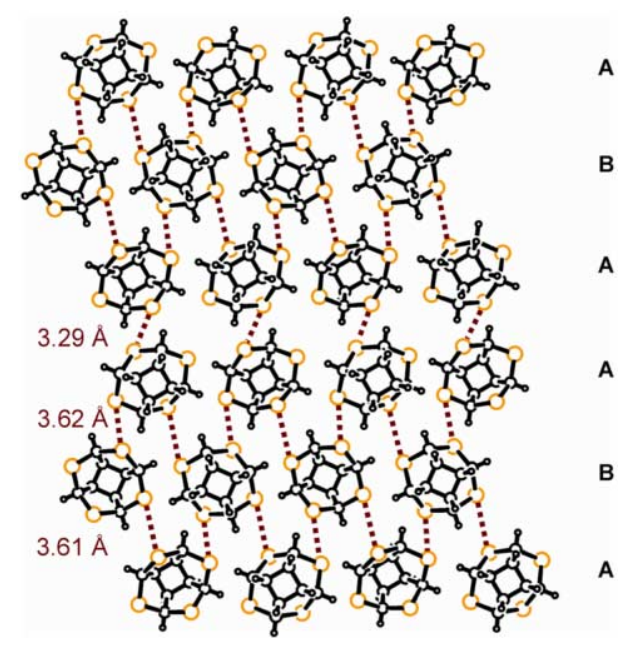

Figure 3. Intercalation of $\mathbf{B}$ molecules between $\mathbf{A}$ columns in the $a c$ plane viewed along $b$-axis. $\mathrm{S} \cdots \mathrm{S}$ contacts are shown in red.

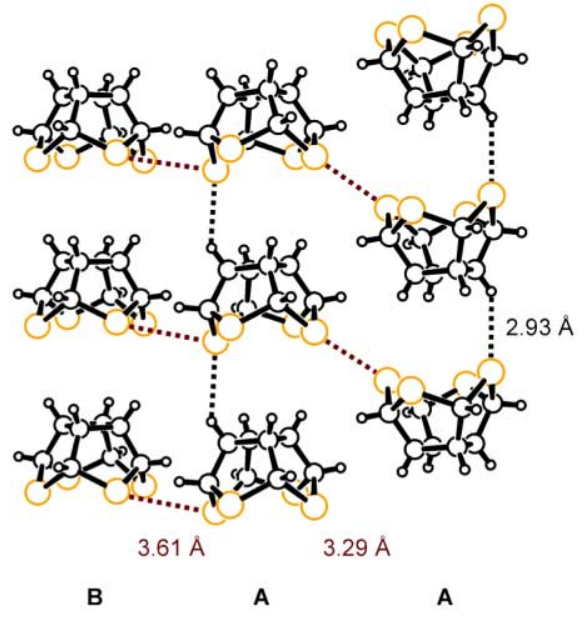

Figure 4. Columnar arrangement of $\mathbf{A}$ molecules in the $a b$ plane through $\mathrm{CH} \cdots \mathrm{S}$ interactions (black). Middle column shows bifurcated $\mathrm{S} \cdots \mathrm{S}$ and $\mathrm{CH} \cdots \mathrm{S}$ contacts.

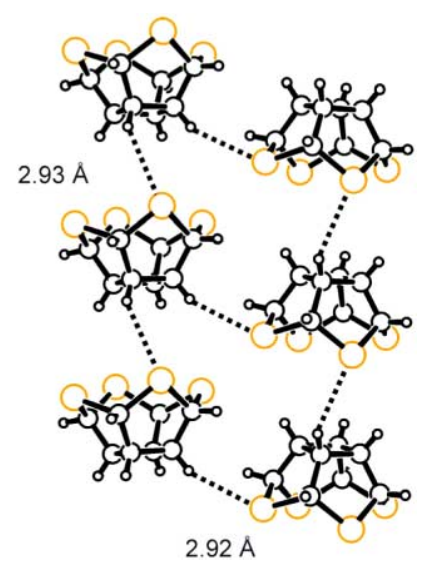

Figure 5. $\mathrm{CH} \cdots \mathrm{S}$ interactions between $\mathbf{A}$ molecules in the $b c$ plane.

It may be instructive to compare the solid state architecture of tetrathiabowl 2c with its oxa-analogue $\mathbf{2 a}$. While both $\mathbf{2 a}$ and $\mathbf{2 c}$ exhibit some similar features, like, alternate concave-convex orientation of bowls, columnar arrangement and participation of cyclobutane hydrogen atoms in $\mathrm{CH} \cdots \mathrm{X}(\mathrm{O}, \mathrm{S})$ interactions, the additionality of the $\mathrm{S} \cdots \mathrm{S}$ interactions in $\mathbf{2 c}$ eventuates in the novel 'host-guest' packing pattern through the selfinclusion phenomenon. Thus, swapping of oxygen and sulphur atoms in these designer bowls leads to pro- 
found alterations in supramolecular architecture and highlights the importance of chalcogen-chalcogen interactions in determining crystal packing. ${ }^{4} \mathrm{We}$ are continuing our efforts to access other thiabowls in the series 1c- $4 c$.

\section{Acknowledgements}

G.M. thanks the Deutsche Forschungsgemeinschaft (DFG) for the award of Mercator Professorship. V.G. thanks JNCASR for the postdoctoral research fellowship. We thank Professor G. Schröder for a generous gift of COT dimer. R.G. and C.S. are grateful to DFG (Graduiertenkolleg 850) for financial support.

\section{References}

1. (a) Olah, G. A. Cage Hydrocarbons; John Wiley and Sons: New York, 1990; (b) Osawa, E.; Yonemitsu, O. Carbocyclic Cage Compounds; VCH: New York, 1992; (c) Hopf, H. Classics in Hydrocarbon Chemistry; WileyVCH: Weinheim, 2000.

2. (a) Mehta, G.; Vidya, R.; Sharma, P. K.; Jemmis, E. D. Tetrahedron Lett. 2000, 41, 2999; (b) Mehta, G.; Vidya, R.; Venkatesan, K. Tetrahedron Lett. 1999, 40, 2417; (c) Mehta, G.; Vidya, R. Tetrahedron Lett. 1997, 38, 4173; (d) Mehta, G.; Vidya, R. Tetrahedron Lett. 1997, 38, 4177; (e) Mehta, G.; Vidya, R. J. Org. Chem. 2001, 66, 6905.

3. (a) Wu, H.-J.; Wu, C.-Y. Tetrahedron Lett. 1997, 38, 2493; (b) Wu, H.-J.; Wu, C.-Y. J. Org. Chem. 1999, 64, 1576.

4. Gleiter, R.; Werz, D. B.; Rausch, B. J. Chem. Eur. J. 2003, 9, 2676 and references cited therein.

5. Perregaard, J.; Scheibye, S.; Meyer, H. J.; Thomsen, I.; Lawesson, S. O. Bull. Soc. Chim. Belg. 1977, 86, 679.

6. Recently, Wu et al. have demonstrated the efficacy of LR in the preparation of thiacage compounds from cyclic acetals and proposed a mechanism. A similar multi-step, iterative pathway might be involved in the formation of 2c from 6-8 and 2a. See: Wu, C.-Y.; Lin, H.-C.; Wang, Z.; Wu, H.-J. J. Org. Chem. 2001, 66, 4610.

7. Schröder, G.; Kirsch, G.; Oth, J. F. M. Chem. Ber. 1974, $107,460$.

8. All compounds reported here were characterized on the basis of their spectral (IR, ${ }^{1} \mathrm{H}$ and ${ }^{13} \mathrm{C}$ NMR and mass) data.
9. The geometry of $\mathbf{2 c}$ was fully optimized resulting in a $C_{4 \mathrm{v}}$ symmetry using the DFT (B3LYP) method applying a 6-311G(d) basis set with the Gaussian 98 program. ${ }^{10}$ Frequency calculations were carried out to confirm the nature of the stationary point, yielding no imaginary frequency for the minimum.

10. Gaussian 98, Revision A.7; Frisch, M. J.; Trucks, G. W.; Schlegel, H. B.; Scuseria, G. E.; Robb, M. A.; Cheeseman, J. R.; Zakrzewski, V. G.; Montgomery, J. A., Jr.; Stratmann, R. E.; Burant, J. C.; Dapprich, S.; Millam, J. M.; Daniels, A. D.; Kudin, K. N.; Strain, M. C.; Farkas, O.; Tomasi, J.; Barone, V.; Cossi, M.; Cammi, R.; Mennucci, B.; Pomelli, C.; Adamo, C.; Clifford, S.; Ochterski, J.; Petersson, G. A.; Ayala, P. Y.; Cui, Q.; Morokuma, K.; Malick, D. K.; Rabuck, A. D.; Raghavachari, K.; Foresman, J. B.; Cioslowski, J.; Ortiz, J. V.; Baboul, A. G.; Stefanov, B. B.; Liu, G.; Liashenko, A.; Piskorz, P.; Komaromi, I.; Gomperts, R.; Martin, R. L.; Fox, D. J.; Keith, T.; Al-Laham, M. A.; Peng, C. Y.; Nanayakkara, A.; Gonzalez, C.; Challacombe, M.; Gill, P. M. W.; Johnson, B.; Chen, W.; Wong, M. W.; Andres, J. L.; Gonzalez, C.; Head-Gordon, M.; Replogle, E. S.; Pople, J. A. Gaussian, Inc., Pittsburgh PA, 1998.

11. Crystal data: Structure was solved by direct methods (SIR92) on an APEX SMART instrument. Refinement was by full-matrix least-squares using SHELXL-97. Crystal system: monoclinic, space group: $P 2 / c$, cell parameters: $a=18.2105(54), \quad b=5.9226(18), c=12.9781(38) \AA$; $\beta=96.429(5)^{\circ} ; \quad V=1390 \quad \AA^{3} ; \quad D_{\text {calcd }}=1.6646 ; \quad \mathrm{mg} / \mathrm{m}^{3} ;$ $F(000)=720.0$; cell formula units $(Z)=6 ; T=273 \mathrm{~K}$; $\lambda=0.71073 \AA ; \mu=9.598 \mathrm{~cm}^{-1} ; R=0.0503$ for $2506 F_{\mathrm{o}}>$ $4 \sigma\left(F_{\mathrm{o}}\right)$ and 0.0584 for all 2838 data $R_{\mathrm{w}}=0.1176, \mathrm{GooF}=$ $S=1.210$, Restrained $\mathrm{GooF}=1.210$ for all data. Crystallographic data have been deposited in the Cambridge Crystallographic Data Center (CCDC-215515).

12. The causative factors for such significant distortion from the $\mathrm{C}_{4 v}$ symmetry in the crystal structure of tetrathiabowl 2c are not clear, particularly in view of the fact that the tetraoxa analogue 2a is essentially $\mathrm{C}_{4 v}$ symmetric. ${ }^{2 \mathrm{~b}}$ The role of $\mathrm{S} \cdots \mathrm{S}$ interactions in engendering such distortions can only be a matter of conjecture.

13. While many short $\mathrm{S} \cdots \mathrm{S}$ and $\mathrm{CH} \cdots \mathrm{S}$ contacts were observed in the crystal structure of $\mathbf{2 c}$, we have used cutoff limits of $\sim 3.6 \AA$ for $\mathrm{S} \cdots \mathrm{S}$ and $3.0 \AA$ for $\mathrm{CH} \cdots \mathrm{S}$ interactions.

14. (a) Bondi, A. J. Phys. Chem. 1964, 68, 441; (b) Taylor, R.; Kennard, O. J. Am. Chem. Soc. 1982, 104, 5083.

15. Novoa, J. J.; Rovira, M. C.; Rovira, C.; Veciana, J.; Tarrés, J. Adv. Mater. 1995, 7, 233. 